\title{
Percutaneous Microwave Ablation of Histologically Proven T1 Renal Cell Carcinoma
}

\author{
B. M. Aarts ${ }^{1,2}$ (1) W. Prevoo ${ }^{1,3}$ - M. A. J. Meier ${ }^{4}$ A. Bex ${ }^{5,6}$ - R. G. H. Beets-Tan ${ }^{1,2}$ • \\ E. G. Klompenhouwer ${ }^{1}$ - F. M. Gómez ${ }^{1,7}$
}

Received: 29 October 2019/ Accepted: 20 January 2020/Published online: 12 February 2020

(C) The Author(s) 2020

\begin{abstract}
Objectives To assess the safety and efficacy of percutaneous microwave ablation (MWA) of histologically proven T1 renal cell carcinoma (RCC).

Methods We analysed patients with a histologically proven RCC $(\leq 7 \mathrm{~cm})$ treated by MWA from April 2012April 2018. Primary and secondary efficacy, local tumour recurrence (LTR), morbidity and mortality were reported. Efficacy was defined as no residual tumour enhancement on follow-up imaging 1 month after the first ablation (primary efficacy) and after re-ablation(s) for residual disease (secondary efficacy). Adverse events (AE) were registered by the Clavien-Dindo classification and the common terminology criteria for AE. Univariable and multivariable logistic regression analyses were performed
\end{abstract}

B. M. Aarts

b.aarts@nki.nl

1 Department of Radiology, The Netherlands Cancer Institute, Plesmanlaan 121, 1066 CX Amsterdam, The Netherlands

2 GROW School for Oncology and Developmental Biology, Maastricht University Medical Centre, P.O. Box 5800, 6202 AZ Maastricht, The Netherlands

3 Department of Radiology, OLVG, Oosterpark 9, 1091 AC Amsterdam, The Netherlands

4 Department of Radiology, Isala Klinieken, Dokter van Heesweg 2, 8025 AB Zwolle, The Netherlands

5 Department of Urology, The Netherlands Cancer Institute, Plesmanlaan 121, 1066 CX Amsterdam, The Netherlands

6 Specialist Centre for Kidney Cancer, Royal Free London NHS Foundation Trust and UCL Division of Surgery and Interventional Science, Pond Street, London NW3 2QG, UK

7 Department of Interventional Radiology, Hospital Clinic Universitari de Barcelona, Carrer de Villarroel 170, 08036 Barcelona, Spain to investigate a relation among pre-treatment factors incomplete ablation and complications.

Results In 100 patients, a total of 108 RCCs (85 T1a and $23 \mathrm{~T} 1 \mathrm{~b})$ were treated by MWA. Median size was $3.2 \mathrm{~cm}$ (IQR 2.4-4.0). Primary efficacy was $89 \% \quad(95 \% \mathrm{CI}$ $0.81-0.94)$ for T1a lesions and $52 \%$ (95\%CI $0.31-0.73$ ) for T1b lesions $(p<0.001)$. Fifteen lesions $(7 \mathrm{~T} 1 \mathrm{a})$ were reablated for residual disease by MWA in one $(n=13)$ and two ( $n=2$, both T1b) sessions resulting in secondary efficacy rates of 99\% (T1a) and 95\% (T1b, $p=0.352$ ). LTR occurred in four tumours (2 T1a, 2 T1b) after 10-60 months. Six (4\%) AEs grade > 3-5 were observed ( 2 T1a, 4 T1b, $p=0.045$ ). Multivariable analysis showed that mR.E.N.A.L. nephrometry was independently associated with incomplete ablation $(p=0.012)$.

Conclusion Microwave ablation is safe and effective for T1a and T1b RCC lesions with a significantly lower primary efficacy for T1b lesions.

Keywords Percutaneous thermal ablation .

Microwave ablation - Renal cell carcinoma $\cdot$ Kidney

$\begin{array}{ll}\text { Abbreviations } & \\ \text { RCC } & \text { Renal cell carcinoma } \\ \text { EAU } & \text { European association of urology } \\ \text { NCCN } & \text { National comprehensive cancer network } \\ \text { PN } & \text { Partial nephrectomy } \\ \text { RFA } & \text { Radiofrequency ablation } \\ \text { CA } & \text { Cryoablation } \\ \text { MWA } & \text { Microwave ablation } \\ \text { R.E.N.A.L. } & \text { Radius, exophytic/endophytic, nearness to } \\ & \text { collecting system or sinus and location } \\ \text { mR.E.N.A.L. } & \text { Modifive to polar lines } \\ \text { AE } & \text { Adverse event }\end{array}$


CTCAE Common terminology criteria for adverse events

LTR Local tumour recurrence

CT Computed tomography

HR Hazard ratio

IQR Interquartile range

RN Radical nephrectomy

ROC Receiver operating characteristics

AUCs Area under the curve

\section{Introduction}

Renal cell carcinoma (RCC) accounts for 3\% of all cancers worldwide [30]. According to the European Association of Urology (EAU) and the National Comprehensive Cancer Network (NCCN) RCC guidelines, partial nephrectomy (PN) is the gold standard for T1a RCC. Percutaneous tumour ablation is reserved for co-morbid patients and patients not eligible for surgery [21, 25]. Although reports show higher local control after PN compared to ablative therapies, similar cancer-specific survival is obtained with less renal function decline for radiofrequency ablation (RFA) and cryoablation (CA) [32].

Details of the different ablation modalities, RFA, MWA and CA, are extensively described in the literature. To summarize, MWA, compared to RFA, achieves higher temperatures in a shorter time less influenced by the heat sink effect. As a result, a fast and large ablation zone with a similar applicator as RFA is achieved. [4, 20] With RFA and MWA, the evolvement of the ablation zone during the procedure is less visible compared to CA [16]. Reports about the efficacy and safety of large cohorts of MWA remain limited, especially for T1b tumours [9, 10].

In this retrospective cohort study, we report the outcomes of patients with a histologically proven RCC treated by means of MWA in a tertiary reference centre. The purpose of this study was to evaluate the safety, efficacy and factors influencing outcome of MWA in T1a and T1b RCC.

\section{Patients and Methods}

\section{Study Population}

The institutional review board of our hospital approved this retrospective study (IRBd18059). The data of all MWAs of our institute were requested through our institutes data desk, and consent of all patients was checked. We included patients treated by MWA for a histologically proven T1 RCC between April 2012 and April 2018. Patients were excluded when prior therapy (chemotherapy, surgical resection or a different ablation modality) for RCC was administrated.

\section{MWA Procedure}

All patients were first discussed in a multidisciplinary tumour board, consisting of urologists, radiologists and medical oncologists to decide patients eligibility for MWA. The MW procedures were performed computed tomography (CT) guided (CT Somatom Sensation Open, Siemens ${ }^{\circledR}$, Munchen, Germany). Patients were treated with two different MW systems (2012-2014: Evident ${ }^{\circledR}$ MW system (Covidien $^{\circledR}$, Dublin, Ireland), 2014-2018: Emprint ${ }^{\circledR} \mathrm{MW}$ system (Medtronic ${ }^{\circledR}$, Dublin, Ireland)). Dissection was performed with $5 \%$ glucose solution plus $10 \%$ iodinated contrast, $\mathrm{CO} 2$ and room air for tumours adjacent to vulnerable structures. Ureteric perfusion with cooled saline was used for tumours close to the collection system and the proximal ureter. Antenna placement was performed with CT fluoroscopy, and optimal position was verified by CT before start of the ablation. After antenna placement, biopsy was performed. In principle, a power of $100 \mathrm{~W}$ was used for 2-10 min according to tumour size. A margin of 5-10 $\mathrm{mm}$ was attempted to achieve complete ablation. Fluoroscopic CT check was performed to monitor the procedure. In larger tumours, the ablation was repeated with different antenna positions to achieve a complete ablation zone. With the Evident ${ }^{\circledR}$ MW system, multiple antennas were placed in the tumour according to physicians choice.

\section{Follow-Up}

An institutional follow-up scheme of multiphase CT scans after 1, 3, 6, 9 and 12 months was executed. Patients with a diminished renal function were followed by (non-)contrast enhanced magnetic resonance imaging (Achieva or Ingenia, Philips Healthcare ${ }^{\circledR}$, Best, the Netherlands). According to agreement with our in-house urologists, follow-up for the first year was performed by the IR at our outpatient clinics. When no recurrence appeared, patients were sent back to the referring urologist. A follow-up scheme of 1 multiphase CT scan a year for 5 years was advised to the referring urologist.

\section{Data Collection and Statistical Analysis}

Tumour characteristics were scored according to the R.E.N.A.L. nephrometry score (radius, exophytic/endophytic, nearness to collecting system or sinus and location 
relative to polar lines) and modified (m)R.E.N.A.L. nephrometry score, as published previously [26]. Adverse events (AEs) during ablation were registered by the common terminology criteria for adverse events (CTCAE), and post-ablation AEs were registered following the ClavienDindo classification. Primary efficacy was defined as no residual tumour enhancement visible at post-contrast $\mathrm{CT}$ or MRI 1 month post-ablation. Secondary efficacy was described as the percentage of tumours successfully treated for residual disease by repeated MWA(s) [1]. Patients treated with another secondary treatment modality (i.e. PN, radical nephrectomy (RN), RFA or CA) were excluded for the secondary efficacy. Local tumour recurrence (LTR) was defined when new enhancement within a successfully treated ablation zone occurred during the follow-up.

Continuous variables are shown as median and interquartile ranges (IQR) and categorical data as numbers and percentages. To test differences between categories, the Chi-square or Fisher exact test was used and for nonparametric continuous variables the Mann-Witney test. To analyse the relationship between pre-treatment factors with incomplete ablations and the occurrence of complications, a logistic regression analysis was performed. Results are presented as odds ratio (OR), 95\% confidence interval (CI) and significance levels. For the multivariable logistic regression analysis, only significant variables from the univariable analysis were included. Significance levels of $p<0.05$ were used. Analyses were performed using Statistical Package for the Social Sciences (SPSS, version 25, Chicago, IL).

\section{Results}

\section{Patient and Tumour Characteristics}

Between April 2012-April 2018, 226 patients underwent a MWA for their renal masses. One hundred and twenty-six patients were excluded because of non-diagnostic biopsy $(n=55)$, benign biopsy $(n=30)$, treatment for recurrence disease after prior treatment $(n=12)$, metastatic disease $(n=23)$, T3 disease $(n=2)$, tumour debulking $(n=2)$, prior chemotherapy for tumour reduction $(n=1)$ and no follow-up imaging available after the MWA $(n=1)$. One hundred patients with 108 histologically proven RCCs were included in this analysis; patient and tumour characteristics are shown in Table 1.

\section{Primary and Secondary Efficacy}

A total of $125 \mathrm{MW}$ ablations were performed in 108 tumours. The Evident ${ }^{\circledR}$ MW system was used in 14 MWAs with the use of multiple antennas (2-3) in 10 tumours. The
Emprint ${ }^{\circledR}$ MW system was used in the other 111 MWAs. Dissection was used in $37 \%$ of the procedures with five ureter perfusions. Patients were mostly placed in the CT scanner in a prone position $(75 \%)$, under epidural $(98 \%)$ or general (2\%) anaesthesia.

Primary efficacy was achieved in 88 lesions (81\%) (Table 2, Fig. 1A-C). T1a lesions had a significantly higher primary efficacy $(89 \%$; CI $0.81-0.94)$ compared to T1b lesions (52\%; CI 0.31-0.73) $(p<0.001)$. Fifteen tumours $(53 \% \mathrm{~T} 1 \mathrm{~b})$ received a second MWA and two T1b tumours a third MWA. Secondary efficacy of MWA was reached in 97\% (101/103) (all tumours), 99\% (82/83) (T1a) and $95 \%(19 / 20)(\mathrm{T} 1 \mathrm{~b}, p=0.352)$. Five tumours $(5 / 20,2$ T1a and 3T1b) were not re-treated by MWA and excluded for the secondary efficacy, but were all successfully treated by means of surgery (PN; T1a) and other ablative techniques (RFA $(1 \mathrm{~T} 1 \mathrm{a}$ tumour $(1 \times$ re-RFA) and $1 \mathrm{~T} 1 \mathrm{~b}$ tumour $(3 \mathrm{x}$ re-RFA)), CA $(n=1 ; \mathrm{T} 1 \mathrm{~b}))$ and no treatment (patients choice). In five lesions, the second MWA was incomplete (1 T1a, $4 \mathrm{~T} 1 \mathrm{~b})$ and were successfully treated with MWA $(n=2)$. In three lesions, another ablative modality was used (CA $(n=2)$ and RFA $(n=1))$.

\section{Adverse Events}

A total of 24 (19\%) AEs were observed after the $125 \mathrm{MW}$ procedures including six major AEs $(4 \%)$ with a significantly higher number of major AEs in T1b tumours ( $2 \mathrm{~T} 1 \mathrm{a}$ $2 \%$ and $4 \mathrm{~T} 1 \mathrm{~b} 13 \%, p=0.045$ ) (Table 3). There was no significant difference in the occurrence of all complications and $\mathrm{T}$ stage (18 T1a $20 \%$ and $6 \mathrm{~T} 1 \mathrm{~b} 18 \%, p=1.000)$. One major $\mathrm{AE}$ consisted of an active bleeding on the control scan during the MWA, which was successfully coiled embolized (CTCAE grade 3). One patient died 13 days after the ablation due to cardiac and renal failure (ClavienDindo grade 5). In two patients, a urinary tract stenosis arose after the MWA (Clavien-Dindo 4a) after 1 and 2 months resulting in a non-functional kidney (see Fig. 1D-F). In three patients, a urinary tract stenosis occurred 1, 2 and 5 months after the MWA without loss of renal function (Clavien-Dindo 1). All five lesions were endophytic T1a lesions, with a close relation to the collection system (4 lesions $<4 \mathrm{~mm}, 1$ lesions $4-7 \mathrm{~mm}$ ). Cooling of the urinary tract system was performed in one lesion. One patient with macroscopic haematuria required transfusion with packed red blood cells and antibiotics (both grade 3). Nineteen (15\%) minor AEs occurred (Clavien-Dindo grade $1+2$ ).

\section{Factors Influencing Outcome}

R.E.N.A.L. nephrometry score (OR 1.56, $p=0.001$ ), mR.E.N.A.L. nephrometry score (OR $1.58, p=0.000)$ and 
Table 1 Pre-treatment characteristics

\begin{tabular}{|c|c|c|c|c|}
\hline & $\begin{array}{l}\text { All } \\
(n=108)\end{array}$ & $\begin{array}{l}\text { T1a } \\
(n=85)\end{array}$ & $\begin{array}{l}\text { T1b } \\
(n=23)\end{array}$ & $p$ value \\
\hline Number of patients & 100 & 77 & 23 & \\
\hline Median age at treatment, IQR & $71(63-77)$ & $69(63-76)$ & $74(63-77)$ & $0.285^{\mathrm{a}}$ \\
\hline Male & $59(59 \%)$ & $48(62 \%)$ & $11(48 \%)$ & $0.235^{\mathrm{b}}$ \\
\hline \multicolumn{5}{|l|}{ History } \\
\hline Cardiovascular & $30(30 \%)$ & $21(25 \%)$ & $9(39 \%)$ & $0.306^{\mathrm{b}}$ \\
\hline Oncological & $38(38 \%)$ & $29(38 \%)$ & $9(39 \%)$ & $0.899^{\mathrm{b}}$ \\
\hline Urological & $22(22 \%)$ & $15(19 \%)$ & $7(30 \%)$ & $0.389^{\mathrm{b}}$ \\
\hline Median size, IQR & $3.2(2.4-4.0)$ & $2.8(2.2-3.5)$ & $4.5(4.3-5.0)$ & $0.000^{\mathrm{a}}$ \\
\hline Laterally & & & & $0.357^{\mathrm{b}}$ \\
\hline Right & $56(52 \%)$ & $42(49 \%)$ & $14(61 \%)$ & \\
\hline Left & $52(48 \%)$ & $43(51 \%)$ & $9(39 \%)$ & \\
\hline Aetiology tumour & & & & $0.096^{\mathrm{b}}$ \\
\hline Clear cell & $68(63 \%)$ & $51(60 \%)$ & 17 (74\%) & \\
\hline Papillary & $22(20 \%)$ & $21(25 \%)$ & $1(4 \%)$ & \\
\hline Type I & 14 & 14 & 0 & \\
\hline Type II & 4 & 3 & 1 & \\
\hline Chromophobe & $4(4 \%)$ & $4(5 \%)$ & 0 & \\
\hline Eosinophilic & $1(1 \%)$ & 0 & $1(4 \%)$ & \\
\hline Undefined renal cell carcinoma & $13(12 \%)$ & $9(11 \%)$ & $4(17 \%)$ & \\
\hline Fuhrman grade & & & & $0.501^{\mathrm{b}}$ \\
\hline 1 & $23(21 \%)$ & $17(20 \%)$ & $6(26 \%)$ & \\
\hline 2 & $32(30 \%)$ & $23(27 \%)$ & $9(39 \%)$ & \\
\hline 3 & $6(6 \%)$ & $5(6 \%)$ & $1(4 \%)$ & \\
\hline Undefined/not possible & $47(44 \%)$ & $40(47 \%)$ & $7(31 \%)$ & \\
\hline Location & & & & $0.175^{\mathrm{b}}$ \\
\hline Exophytic & $61(57 \%)$ & $44(52 \%)$ & $17(74 \%)$ & \\
\hline$<50 \%$ exophytic & $11(10 \%)$ & $10(12 \%)$ & $1(4 \%)$ & \\
\hline Endophytic & $36(33 \%)$ & $31(36 \%)$ & $5(22 \%)$ & \\
\hline Anterior & $26(24 \%)$ & $23(27 \%)$ & $3(13 \%)$ & $0.076^{2}$ \\
\hline Posterior & $62(57 \%)$ & $44(52 \%)$ & $18(78 \%)$ & \\
\hline Mid & $20(19 \%)$ & $18(21 \%)$ & $2(9 \%)$ & \\
\hline Lower pole & $31(29 \%)$ & $25(29 \%)$ & $6(26 \%)$ & $0.874^{\mathrm{b}}$ \\
\hline Upper pole & $35(32 \%)$ & $28(33 \%)$ & $10(43 \%)$ & \\
\hline Inter pole & $42(39 \%)$ & $32(38 \%)$ & $7(30 \%)$ & \\
\hline Distance to collecting system & & & & $0.004^{b}$ \\
\hline$>7 \mathrm{~mm}$ & $66(61 \%)$ & $58(68 \%)$ & $8(35 \%)$ & \\
\hline $4-7 \mathrm{~mm}$ & $11(10 \%)$ & $9(11 \%)$ & $2(9 \%)$ & \\
\hline$<4 \mathrm{~mm}$ & $31(29 \%)$ & $18(21 \%)$ & $13(57 \%)$ & \\
\hline Distance to polar lines & & & & $0.155^{2}$ \\
\hline Entirely above/below & $62(57 \%)$ & $52(61 \%)$ & $10(43 \%)$ & \\
\hline Lesion crosses 1 polar line & $27(25 \%)$ & $21(25 \%)$ & $6(22 \%)$ & \\
\hline$>50 \%$ of mass across polar line & $19(18 \%)$ & $12(14 \%)$ & $7(35 \%)$ & \\
\hline R.E.N.A.L. nephrometry score & $6(4-8)$ & $5(4-7)$ & $7(6-9)$ & $0.000^{\mathrm{a}}$ \\
\hline Low (4-6) & $68(63 \%)$ & $60(71 \%)$ & $8(35 \%)$ & $0.002^{b}$ \\
\hline Intermediate (7-9) & $28(26 \%)$ & $17(20 \%)$ & $12(52 \%)$ & $0.007^{\mathrm{b}}$ \\
\hline High (10-12) & $12(11 \%)$ & $8(9 \%)$ & $4(18 \%)$ & $0.280^{\mathrm{b}}$ \\
\hline m.R.E.N.A.L. nephrometry score & $6(5-9)$ & $5(4-8)$ & $8(7-10)$ & $0.000^{\mathrm{a}}$ \\
\hline Low (4-6) & $59(55 \%)$ & $55(65 \%)$ & $4(17 \%)$ & $0.000^{\mathrm{b}}$ \\
\hline Intermediate (7-9) & $29(27 \%)$ & $19(23 \%)$ & $10(44 \%)$ & $0.062^{\mathrm{b}}$ \\
\hline High (10-12) & $20(19 \%)$ & $11(13 \%)$ & $9(40 \%)$ & $0.004^{\mathrm{a}}$ \\
\hline
\end{tabular}

${ }^{\mathrm{a}} \mathrm{Mann}-\mathrm{Witney}$ test ${ }^{\mathrm{b}} \mathrm{Chi}$-square, IQR interquartile range

Bold values indicate the significance level of $p<0.05$ 
Table 2 Efficacy results for patients treated for a T1a and T1b RCC lesion

\begin{tabular}{llllr}
\hline & All & T1a & T1b & $p$ value \\
\hline Primary efficacy & $88 / 108(81 \%)$ & $76 / 85(89 \%)$ & $12 / 23(52 \%)$ & $<\mathbf{0 . 0 0 1}$ \\
Remnant & $20 / 108(19 \%)$ & $9 / 85(11 \%)$ & $11 / 23(48 \%)$ & $<\mathbf{0 . 0 0 1}$ \\
Secondary efficacy & $101 / 103(98 \%)$ & $82 / 83(99 \%)$ & $19 / 20(95 \%)$ & 0.352 \\
Recurrence & $3 / 105(3 \%)$ & $2 / 83(2 \%)$ & $2 / 22(9 \%)$ & 0.193 \\
\hline
\end{tabular}

Bold values indicate the significance level of $p<0.05$
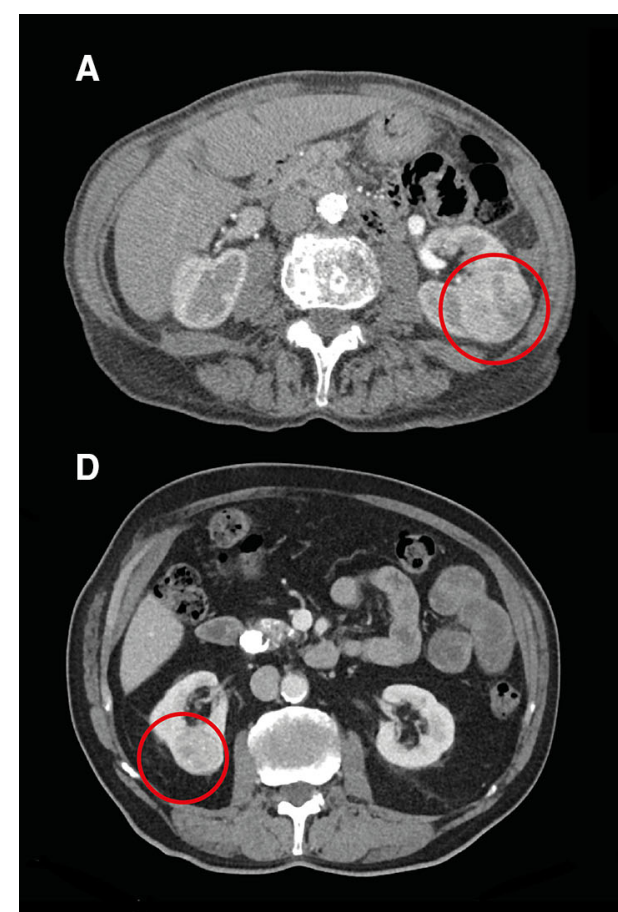

$\mathbf{E}$
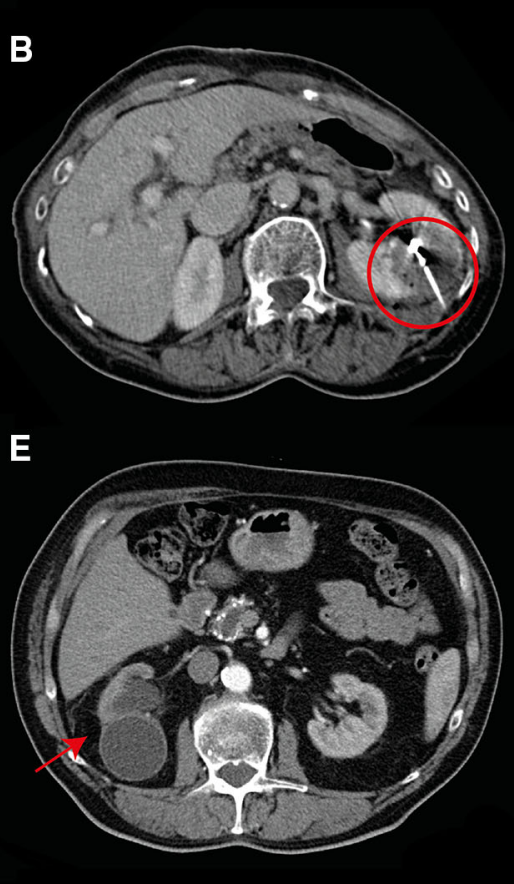

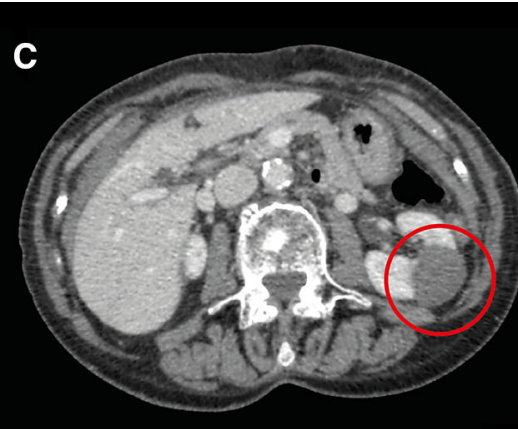

$\mathbf{F}$

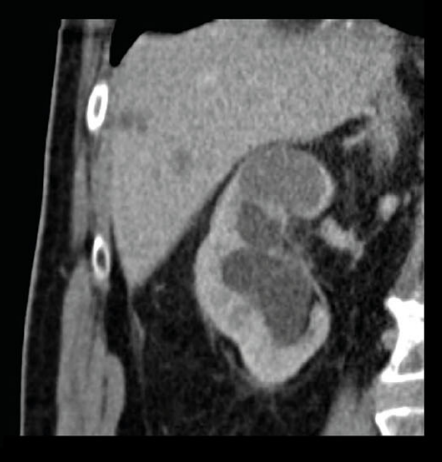

Fig. 1 A-C Microwave ablation (MWA) of a T1b tumour (A) before MWA (B) during MWA (C) 1 year after MWA: complete ablation. D-F endophytic T1a lesion with a close relation to the collecting system (D). E + F 9 months after complete ablation, hydronephrosis

tumour aetiology (clear cell vs non-clear cell OR 0.11, $p=0.034$ ) were significantly associated with an incomplete ablation; however, only the mR.E.N.A.L. nephrometry score remained significantly associated in the multivariable regression analysis $(\mathrm{OR}=3.854 p=0.012$ ) (Table 4). Of the mR.E.N.A.L nephrometry score, size ( $>3$ and $>4)$, nearness to the collecting system $(<4 \mathrm{~mm})$ and distance to the polar lines (score 3 ) were significantly associated with an incomplete ablation.

Univariable analysis showed that only the R.E.N.A.L. nephrometry score (OR $1.308, p=0.013$ ) and mR.E.N.AL. nephrometry score (OR 1.577, $p=0.016$ ) were associated with the occurrence of complications. Of the (m)RENAL nephrometry score, only the nearness to the collecting system $(<4 \mathrm{~mm})$ was significantly associated with the occurrence of complications. of the kidney visible due to an urinary tract stenosis that occurred 3 months after the MWA (kidney function from 45 to $19 \mathrm{ml} / \mathrm{min} /$ $1.73 \mathrm{~m} 2$ ) (NB this patient is familiar with liver cysts)

\section{Follow-Up}

Median follow-up time was 19 months (IQR 12-35 months; min-max 0-78 months, 90 patients $(90 \%)$ 1-year follow-up available). During this period, four (4\%) tumours showed LTR ( 2 T1a and 2 T1b tumours) after 10, 13, 26 and 60 months. One recurrence was successfully treated by MWA and two recurrences by another modality (CA). One of the recurrences has not been treated yet. One patient treated by MWA for bilateral chromophobe RCC tumours developed a new lesion in the same kidney for which he underwent active surveillance. Five patients (4 T1a tumours, 1 T1b tumours) developed metastases of which two were histologically proven RCC. During followup, no patient died of RCC. 
Table 3 Adverse events during and post-ablation

\begin{tabular}{llll}
\hline Adverse events & Grade $^{\mathrm{a}}$ & $n$ & $\mathrm{~T}$ stage \\
\hline $\begin{array}{l}\text { During ablation } \\
\text { Tumour bleeding required embolization }\end{array}$ & 3 & 1 & $\mathrm{~T} 1 \mathrm{~b}$ \\
Post-ablation & 5 & 1 & $\mathrm{~T} 1 \mathrm{~b}$ \\
Dead within 30 days & $4 \mathrm{a}$ & 2 & $\mathrm{~T} 1 \mathrm{a}$ \\
Urinary tract stenosis with renal function loss & 3 & 2 & $\mathrm{~T} 1 \mathrm{~b}$ \\
Ureteral blood loss required endoscopic intervention & 2 & 2 & $\mathrm{~T} 1 \mathrm{a}, \mathrm{b}$ \\
Infection treated with antibiotics & 1 & 3 & $\mathrm{~T} 1 \mathrm{a}$ \\
Urinary tract stenosis (without renal function loss) & 1 & 4 & $\mathrm{~T} 1 \mathrm{a}, \mathrm{b}$ \\
Self-limiting (peri-renal or liver) bleeding & 1 & 3 & $\mathrm{~T} 1 \mathrm{a}$ \\
Pneumothorax & 1 & 1 & $\mathrm{~T} 1 \mathrm{a}$ \\
Sensibility loss of skin & 1 & 2 & $\mathrm{~T} 1 \mathrm{a}$ \\
Pain & 1 & 2 & $\mathrm{~T} 1 \mathrm{a}, \mathrm{b}$ \\
Nausea & 1 & 1 & $\mathrm{~T} 1 \mathrm{a}$ \\
Skin burn & & & \\
\hline according to the common terminology criteria for adverse events during ablation and according to the \\
Clavien-Dindo Classification post-ablation
\end{tabular}

\section{Discussion}

Percutaneous ablation is considered as treatment option in co-morbid patients with a T1 RCC tumour not eligible for PN [21, 25]. RFA and CA are widely applied and established ablation techniques for RCC that are included in the guidelines contrary to MWA which has still limited supportive data [21, 25, 27].

In this study, we show the result of 108 RCCs treated with MWA. There was a significantly higher primary efficacy for T1a tumours (89\%) compared to T1b tumours (52\%). In the 125 performed MWAs, 19\% AEs were observed, mostly low grade (15\%), with a significantly higher number of major AEs in T1b tumours (13\% T1b vs $2 \%$ T1a, $p=0.045)$. The R.E.N.A.L. score and mR.E.N.A.L. nephrometry score were related to incomplete first ablation and the occurrence of complications. The factors, size $(>3 \mathrm{~cm}$ and $>4 \mathrm{~cm}$ ), nearness to the collecting system $(<4 \mathrm{~mm})$ and distance to the polar lines (score 3 ) of the mR.E.N.A.L score were associated with incomplete ablation and nearness to the collecting system $(<4 \mathrm{~mm})$ for the occurrence of complications.

For all primary MWAs, a primary efficacy of $81 \%$ was observed with a primary efficacy of $89 \%$ for T1a tumours. After repeated MWA(s), a secondary efficacy of $99 \%$ was reached for T1a tumours. In the literature, primary efficacy rates of MWA from 84.6 to $100 \%$ are reported $[8,11,14,22,29]$. Therefore, the primary and secondary efficacy of T1a tumours underpins the existing evidence supporting MWA for the treatment of T1a RCC lesions.
The primary efficacy of T1b tumours $(52 \%)$ was significantly lower compared to T1a tumours $(p<0.001)$. In $48 \%$ of the T1b lesions, a second or third ablation was performed to achieve a complete tumour ablation resulting in a secondary efficacy of $95 \%$. In the literature, lower efficacy rates of percutaneous ablation are described for tumours over $4 \mathrm{~cm}$ [29] which is in line with our findings. We show that repeated MW ablations can achieve high efficacy rates even in large tumours. Besides the tumour size, our cohort contained difficult tumours with a close relation to the collecting system. Reports of percutaneous ablation of T1b RCCs by MWA are rare, and series are small [3, 9]. Primary efficacy rates between 75 and $100 \%$ were reported in 12 and $7 \mathrm{~T} 1 \mathrm{~b}$ tumours, respectively $[12,33]$. In the literature, $\mathrm{CA}$ is more commonly used as ablation technique for $\mathrm{T} 1 \mathrm{~b}$ lesions with primary efficacy rates ranging from 76 to $97.2 \%$ [2, 5, 13, 15]. Our results show that MWA can also be used and chosen as a treatment modality in T1b tumours with consideration of a second ablation. Future cost-effectiveness studies have to show the exact place of the difference ablation techniques for RCC.

The overall AE rate of $19 \%$ was relatively high compared to previous percutaneous ablation and surgical studies [9, 32]. However, most AEs were low grade (15\%) with minimal consequences for the patient. In our series, we found a significant difference between $\mathrm{T} 1 \mathrm{a}$ and $\mathrm{T} 1 \mathrm{~b}$ tumour for the occurrence of major AEs. Five patients had a stenosis of the urinary tract, 1-5 months after MWA that resulted in renal function loss in two patients. Nearness to the collecting system was significantly associated with incomplete ablation and complications. Therefore, we 
Table 4 Pretreatment factors and their association with an incomplete ablation and the occurrence of complications

\begin{tabular}{|c|c|c|c|c|c|c|c|}
\hline \multirow[t]{2}{*}{ Variable } & \multirow[t]{2}{*}{ Test } & \multicolumn{3}{|c|}{ Univariable $^{\mathrm{a}}$} & \multicolumn{3}{|c|}{ Multivariable $^{\mathrm{b}}$} \\
\hline & & OR & $95 \% \mathrm{CI}$ & $p$ value & OR & $95 \% \mathrm{CI}$ & $p$ value \\
\hline \multicolumn{8}{|l|}{ Incomplete ablation } \\
\hline Tumour aetiology & Clear cell versus non-clear cell & 0.107 & $0.01-0.85$ & 0.034 & 0.077 & $0.04-1.3$ & 0.077 \\
\hline \multirow[t]{2}{*}{ Fuhrman grade $^{c}$} & Grade 1 versus grade $2+3$ & 1.286 & $0.4-4.3$ & 0.688 & - & - & - \\
\hline & Grade 1 versus unknown & 0.429 & $0.1-1.7$ & 0.221 & - & - & - \\
\hline Age & Continue & 1.005 & $0.96-1.06$ & 0.833 & - & - & - \\
\hline Gender & Male versus Female & 0.770 & $0.3-2.1$ & 0.600 & - & - & - \\
\hline History cardiovascular & Yes versus no & 0.714 & $0.2-2.2$ & 0.551 & - & - & - \\
\hline History oncological & Yes versus no & 0.492 & $0.2-1.3$ & 0.157 & - & - & - \\
\hline History urological & Yes versus no & 0.882 & $0.3-2.7$ & 0.882 & - & - & - \\
\hline \multirow[t]{3}{*}{ Tumour location } & Left versus right & 1.500 & $0.6-4.0$ & 0.421 & - & - & - \\
\hline & Anterior versus posterior & 0.391 & $0.08-1.9$ & 0.242 & - & - & - \\
\hline & Anterior versus inter & 0.720 & $0.2-2.4$ & 0.589 & - & - & - \\
\hline System & Emprint versus evident & 0.342 & $0.1-1.2$ & 0.086 & - & - & - \\
\hline R.E.N.A.L. nephrometry score & Continue & 1.559 & $1.2-2.0$ & 0.001 & 0.356 & $0.1-1.1$ & 0.069 \\
\hline mR.E.N.A.L. nephrometry score & Continue & 1.577 & $1.2-2.0$ & 0.000 & 3.854 & 1.3-11 & 0.012 \\
\hline \multicolumn{8}{|l|}{ Complications } \\
\hline Age & Continue & 0.994 & $0.95-1.0$ & 0.772 & - & - & - \\
\hline Gender & Male versus female & 1.063 & $0.4-2.6$ & 0.895 & - & - & - \\
\hline History cardiovascular & Yes versus no & 0.729 & $0.3-2.0$ & 0.542 & - & - & - \\
\hline History oncological & Yes versus no & 0.941 & $0.4-2.3$ & 0.895 & - & - & - \\
\hline History urological & Yes versus no & 1.234 & $0.4-3.6$ & 0.704 & - & - & - \\
\hline \multirow[t]{3}{*}{ Tumour location } & Left versus right & 1.346 & $0.6-3.3$ & 0.517 & - & - & - \\
\hline & Anterior versus posterior & 0.682 & $0.3-2.0$ & 0.521 & - & - & - \\
\hline & Anterior versus inter & 0.692 & $0.2-2.7$ & 0.598 & - & - & - \\
\hline Dissection & Yes versus no & 1.091 & $0.4-2.8$ & 0.856 & - & - & - \\
\hline System & Emprint versus evident & 1.314 & $0.3-5.2$ & 0.697 & - & - & - \\
\hline R.E.N.A.L. nephrometry score & Continue & 1.308 & 1.1-1.6 & 0.013 & - & - & - \\
\hline mR.E.N.A.L. nephrometry score & Continue & 1.226 & 1.1-1.5 & 0.016 & - & - & - \\
\hline
\end{tabular}

Bold values indicate the significance level of $p<0.05$

${ }^{a}$ In the univariable analysis, all variables were analysed to determine the relation of (m)R.E.N.A.L. nephrometry score and their components with incomplete ablation and complication

${ }^{\mathrm{b}}$ In het multivariable analysis, only the significant variables from the univariable factors were used

${ }^{c}$ Fuhrman grade is a nuclear grading system of clear cell RCC that evaluated the nuclear size, shape and nucleolar prominence

suggest caution during MWA for lesions close to the collecting system. In the literature, 13 cases of injury to the urinary tract system after MWA are reported [7, 11, 19, 23, 31, 33]. Klapperich et al. observed six asymptomatic urinomas that resulted in renal cortex volume loss in three patients [19]. Preclinical work on a histologically level shows damage of MWA to the collecting system by direct puncture of the collecting system and heating of the urine during the ablation [24, 28]. Damage to the gastrointestinal tract was reported by others, but not observed in the current study [16, 18].

Multivariable analysis showed an independent association of the mR.E.N.A.L. nephrometry score for an incomplete first ablation. In addition, univariable analysis showed a relation of R.E.N.A.L. and m.R.E.N.A.L. nephrometry score with the occurrence of complications. These results are in line with Ierardi et al. that also reported an association of the (m)R.E.N.A.L. nephrometry score with incomplete ablation and complications after MWA [17] and Camacho et al. that first described this association after RFA and CA [6]. On the contrary, Klapperich et al. only found an association between local recurrence after MWA and tumour histology characteristic, and not between the R.E.N.A.L. score and local recurrence [19]. Shakeri et al. observed a significantly higher median tumour size in lesions that required a second MWA, but no association with tumour location and R.E.N.A.L score [29]. Also, Wells et al. did not find an association with the RENAL score and treatment outcome [33]. These reports are 
all opposite to our findings which may suggest that MWA is not as straight forward as previously reported.

The LTR in this study was $4 \%$ over a 108 histologically proven RCCs. In the literature, LTR ranges from 0 to $17 \%$ [7, 12, 29], but most papers included every renal lesions without excluding non-diagnostic or benign lesions whereby efficacy and recurrence rates might be overestimated $[23,31,33]$. Surprisingly, the time to LTR was long in this current cohort which could be explained by the difficulties in detecting of recurrences in hypo-vascular tumours and slow growth rates of low-grade tumours.

Limitations of this study include a single-centre retrospective study whereby details of the MW procedure were not complete with the lack of in-house long-term follow-up ( $>1$ year) in some patients. Ideally, we would describe a larger cohort, but the peri-operative biopsy strategy resulted in some non-diagnostic and benign lesions.

In conclusion, primary efficacy of MWA in T1a tumours was significantly higher compared to T1b tumours. Repeated ablation was necessary in $19 \%$ achieving efficacy rates of 95\% (T1a) and 99\% (T1b). Low-grade AEs were seen after MWA whereby close monitoring of the urinary tract is recommended following ablation of tumours adjacent to the urinary tract. Incomplete ablation was more often seen in lesions with a larger size with a close relation to the collecting system and the polar lines accompanied expressed in a higher mR.E.N.A.L. nephrometry score. Prospective data have to determine the exact position of MWA for the treatment of RCC.

Funding This study was not supported by any funding.

\section{Compliance with Ethical Standards}

Conflict of interest W. Prevoo was proctor for the Emprint system during the study period. The rest of the authors declare that they have no conflict of interest.

Ethical Approval All procedures performed in studies involving human participants were in accordance with the ethical standards of the institutional and/or national research committee and with the 1964 Declaration of Helsinki and its later amendments or comparable ethical standards.

Informed Consent For this type of study, formal consent is not required.

Consent for Publication Consent for publication was obtained for every individual person's data included in the study.

Open Access This article is licensed under a Creative Commons Attribution 4.0 International License, which permits use, sharing, adaptation, distribution and reproduction in any medium or format, as long as you give appropriate credit to the original author(s) and the source, provide a link to the Creative Commons licence, and indicate if changes were made. The images or other third party material in this article are included in the article's Creative Commons licence, unless indicated otherwise in a credit line to the material. If material is not included in the article's Creative Commons licence and your intended use is not permitted by statutory regulation or exceeds the permitted use, you will need to obtain permission directly from the copyright holder. To view a copy of this licence, visit http://creativecommons. org/licenses/by/4.0/.

\section{References}

1. Ahmed M. Image-guided tumor ablation: standardization of terminology and reporting criteria-a 10-year update. Radiology. 2014;273(1):241-60.

2. Atwell TD, Vlaminck JJ, Boorjian SA, et al. Percutaneous cryoablation of stage T1b renal cell carcinoma: technique considerations, safety, and local tumor control. J Vasc Interv Radiol. 2015;26(6):792-9.

3. Best SL, Park SK, Youssef RF, et al. Long-term outcomes of renal tumor radio frequency ablation stratified by tumor diameter: size matters. J Urol. 2012;187(4):1183-9.

4. Brace CL. Radiofrequency and microwave ablation of the liver, lung, kidney, and bone: what are the differences? Curr Probl Diagn Radiol. 2009;38(3):135-43.

5. Buy X, Lang H, Garnon J, Sauleau E, Roy C, Gangi A. Percutaneous renal cryoablation: prospective experience treating 120 consecutive tumors. AJR Am J Roentgenol. 2013;201(6):1353-61.

6. Camacho JC, Kokabi N, Xing M, et al. R.E.N.A.L. (Radius, exophytic/endophytic, nearness to collecting system or sinus, anterior/posterior, and location relative to polar lines) nephrometry score predicts early tumor recurrence and complications after percutaneous ablative therapies for renal cell carcinoma: a 5-year experience. J Vasc Interv Radiol. 2015;26(5):686-93.

7. Castle SM, Salas N, Leveillee RJ. Initial experience using microwave ablation therapy for renal tumor treatment: 18-month follow-up. Urology. 2011;77(4):792-7.

8. Chan P, Velasco S, Vesselle G, et al. Percutaneous microwave ablation of renal cancers under CT guidance: safety and efficacy with a 2-year follow-up. Clin Radiol. 2017;72(9):786-92.

9. Choi SH, Kim JW, Kim JH, Kim KW. Efficacy and safety of microwave ablation for malignant renal tumors: an updated systematic review and meta-analysis of the literature since 2012 . Korean J Radiol. 2018;19(5):938-49.

10. Cornelis FH, Marcelin C, Bernhard JC. Microwave ablation of renal tumors: a narrative review of technical considerations and clinical results. Diagn Interv Imaging. 2017;98(4):287-97.

11. Dong X, Li X, Yu J, Yu MA, Yu X, Liang P. Complications of ultrasound-guided percutaneous microwave ablation of renal cell carcinoma. Onco Targets Ther. 2016;9:5903-9.

12. Gao Y, Liang P, Yu X, et al. Microwave treatment of renal cell carcinoma adjacent to renal sinus. Eur J Radiol. 2016;85(11):2083-9.

13. Gunn AJ, Joe WB, Salei A, et al. Percutaneous cryoablation of stage T1b renal cell carcinoma: safety, technical results, and clinical outcomes. Cardiovasc Interv Radiol. 2019;42(7):970-8.

14. Hao G, Hao Y, Cheng Z, et al. Local tumor progression after ultrasound-guided percutaneous microwave ablation of stage T1a renal cell carcinoma: risk factors analysis of 171 tumors. Int $\mathrm{J}$ Hyperth. 2018;35(1):62-70.

15. Hebbadj S, Cazzato RL, Garnon J, et al. Safety considerations and local tumor control following percutaneous image-guided cryoablation of T1b renal tumors. Cardiovasc Interv Radiol. 2018;41(3):449-58.

16. Hinshaw JL, Lubner MG, Ziemlewicz TJ, Lee FT Jr, Brace CL. Percutaneous tumor ablation tools: microwave, radiofrequency, 
or cryoablation-what should you use and why? Radiographics. 2014;34(5):1344-62.

17. Ierardi AM, Puliti A, Angileri SA, et al. Microwave ablation of malignant renal tumours: intermediate-term results and usefulness of RENAL and mRENAL scores for predicting outcomes and complications. Med Oncol. 2017;34(5):97.

18. Janzen NK, Perry KT, Han KR, et al. The effects of intentional cryoablation and radio frequency ablation of renal tissue involving the collecting system in a porcine model. J Urol. 2005;173(4):1368-74.

19. Klapperich ME, Abel EJ, Ziemlewicz TJ, et al. Effect of tumor complexity and technique on efficacy and complications after percutaneous microwave ablation of stage T1a renal cell carcinoma: a single-center, retrospective study. Radiology. 2017;284(1):272-80.

20. Laeseke PF, Lee FT Jr, Sampson LA, van der Weide DW, Brace CL. Microwave ablation versus radiofrequency ablation in the kidney: high-power triaxial antennas create larger ablation zones than similarly sized internally cooled electrodes. J Vasc Interv Radiol. 2009;20(9):1224-9.

21. Ljungberg B, Albiges L, Abu-Ghanem Y, et al. European association of urology guidelines on renal cell carcinoma: the 2019 update. Eur Urol. 2019;75(5):799-810.

22. Maciolek KA, Abel EJ, Posielski NM, et al. Tumor location does not impact oncologic outcomes for percutaneous microwave ablation of clinical T1a renal cell carcinoma. Eur Radiol. 2019;29(11):6319-29.

23. Mansilla AV, Bivins EE Jr, Contreras F, Hernandez MA, Kohler N, Pepe JW. CT-guided microwave ablation of 45 renal tumors: analysis of procedure complexity utilizing a percutaneous renal ablation complexity scoring system. J Vasc Interv Radiol. 2017;28(2):222-9.

24. Moore C, Salas N, Zaias J, Shields J, Bird V, Leveillee R. Effects of microwave ablation of the kidney. $\mathrm{J}$ Endourol. 2010;24(3):439-44.
25. Motzer RJ, Jonasch E, Agarwal N, et al. Kidney cancer, version 2.2017, NCCN clinical practice guidelines in oncology. J Natl Compr Cancer Netw. 2017;15(6):804-34.

26. Mouli SK, McDevitt JL, Su YK, et al. Analysis of the RENAL and mRENAL scores and the relative importance of their components in the prediction of complications and local progression after percutaneous renal cryoablation. J Vasc Interv Radiol. 2017;28(6):860-7.

27. Prins FM, Kerkmeijer LGW, Pronk AA, et al. Renal cell carcinoma: alternative nephron-sparing treatment options for small renal masses, a systematic review. J Endourol. 2017;31(10):963-75.

28. Schmitz JJ, Schmit GD, Viers BR, Atwell TD. Renal microwave ablation resulting in ureteropelvic junction stricture remote from the ablation site. J Vasc Interv Radiol. 2017;28(9):1278-80.

29. Shakeri S, Afshari Mirak S, Mohammadian Bajgiran A, et al. The effect of tumor size and location on efficacy and safety of USand CT- guided percutaneous microwave ablation in renal cell carcinomas. Abdom Radiol (NY). 2019;44(6):2308-15.

30. Siegel RL, Miller KD, Jemal A. Cancer statistics, 2018. CA Cancer J Clin. 2018;68(1):7-30.

31. Thompson SM, Schmitz JJ, Thompson RH, et al. Introduction of microwave ablation into a renal ablation practice: valuable lessons learned. AJR Am J Roentgenol. 2018;211(6):1381-9.

32. Uhlig J, Strauss A, Rucker G, et al. Partial nephrectomy versus ablative techniques for small renal masses: a systematic review and network meta-analysis. Eur Radiol. 2019;29(3):1293-307.

33. Wells SA, Wheeler KM, Mithqal A, Patel MS, Brace CL, Schenkman NS. Percutaneous microwave ablation of T1a and T1b renal cell carcinoma: short-term efficacy and complications with emphasis on tumor complexity and single session treatment. Abdom Radiol (NY). 2016;41(6):1203-11.

Publisher's Note Springer Nature remains neutral with regard to jurisdictional claims in published maps and institutional affiliations. 